\title{
Construction and Development of Teacher Teams in Secondary Colleges of Applied Universities Under the Background of Creating a First-class Undergraduate Education
}

\author{
$\mathrm{Na} \mathrm{Mi} i^{1, a, *}$ \\ ${ }^{1}$ Southeast University Chengxian College, Dongda Road No.6, Nanjing, China \\ ${ }^{a}$ Email:410619052@qq.com
}

\begin{abstract}
Creating a first-class undergraduate education is an important foundation for building a world-class university and an important support for building a first-class discipline. The teachers in the secondary colleges of universities are the direct undertakers of various teaching and research work, the only carriers for the social functions of universities to play a role, and the source of motivation for the construction of first-class undergraduate education. Strengthen the construction of teacher teams in secondary colleges, and implement the service and management of teachers. Only in this way can the enthusiasm of teachers be effectively brought into play, and professional vitality can be stimulated, thereby creating a team of teachers with strong political quality, superb professional ability, and becoming a world-class teacher Team.
\end{abstract}

Keywords: First-class Undergraduate Education; Applied Universities; Construction and Development of Teacher Teams

\section{INTRODUCTION}

Applied undergraduate education has played an active role in cultivating high-level applied talents in social and economic development, and has played an active role in promoting the popularization of higher education in China. In the construction of first-class undergraduates, applied universities should, on the basis of the actual implementation of the national "double first-class" construction master plan, realize connotative development based on their own characteristics, actively promote internal mechanism reforms, and improve management systems. The development direction is to establish a high-level applied university that cultivates first-class applied talents. Secondary college teachers are the direct undertakers of various teaching and research work in universities, the only carrier for the social functions of universities to play a role, and the source of motivation for the construction of first-class undergraduate majors ${ }^{[1]}$. Strengthening the construction of the teaching team of secondary colleges, and realizing the service and management of teachers, can effectively give play to the enthusiasm of teachers, stimulate professional vitality, and create a world-class teaching team with strong political quality, superb professional ability. From the aspects of optimizing the structure of the faculty team, creating a professional team with unique advantages, and improving teacher evaluation and incentive mechanisms, this research helps the secondary colleges of applied universities to build a professional construction path that conforms to their own professional characteristics and advances to a world-class level.

\section{THE CHARACTERISTICS OF TEACHER TEAM BUILDING FACING FIRST-CLASS UNDERGRADUATE EDUCATION}

The construction of first-class undergraduate education is not accomplished overnight. It requires the collaborative construction and long-term accumulation of teachers, teaching materials, courses, platforms and other aspects. Among them, the establishment of a team of teachers with comprehensive qualities and strong abilities is the foundation. Need to have professional 
leaders who can lead the reform and innovation of curriculum system, teaching material construction, teaching content, teaching methods and means; need full-time and part-time teachers with reasonable age structure, title structure, and professional structure; need a teaching and research team with obvious professional characteristics to closely follow the characteristics of the surrounding industries and aim at the development of the regional economy; need a vigorous teacher evaluation and incentive mechanism that guides teachers to not only focus on teaching, but also mobilize their enthusiasm for scientific research and innovation. This is the first-class teacher team with long-term mechanism for the development of first-class undergraduates ${ }^{[2]}$.

\section{THE STATUS QUO OF TEACHER TEAM CONSTRUCTION IN SECONDARY COLLEGES OF APPLIED UNIVERSITIES}

Over the years, with the improvement of college admissions mechanisms, the state has given universities the right to autonomously use people in accordance with relevant regulations and simplified the admission procedures. Under the current secondary management system of schools and colleges generally implemented in domestic universities, the management of teachers has gradually been delegated to the secondary colleges under the overall management of schools. How to make good use of responsibilities and rights, give full play to the main role of the secondary college, stimulate the vitality of the college, improve the sense of professional belonging of the teachers of the college, improve the teaching ability of teachers, and promote the improvement of teaching quality, so as to build a team of high-quality, professional and innovative college teachers with superb professional ability and superb education level is a problem that the current secondary colleges urgently need to face and solve.

\subsection{The Structure of the Faculty Team Is Unreasonable}

"To rejuvenate the country must first strengthen the teacher." Secondary colleges are important organizations of universities, a solid framework for supporting schools, and the foundation for universities to realize social education. The quality of the faculty of secondary colleges directly affects the development of the overall teaching quality of universities. First-class majors must be equipped with first-class teachers, and the rationality of the team's structure is the cornerstone of development. Under the "dual leader" system, in the organizational structure of the secondary college with the dean as the administrative centre and the senior professional title teacher as the academic centre, the structure of the faculty is still generally insufficient in three aspects: age structure, professional title structure, and professional structure. The age structure and title structure directly affect the vitality and strength of the team. At present, there is a general shortage of young and middle-aged academic leaders and high-level managers, which is detrimental to the construction of the discipline echelon and the development of characteristic disciplines. In terms of professional structure, many colleges and universities still have a large proportion of teachers who graduated from their own schools and their majors. Taking computer majors as an example, most teachers graduated from computer science and technology majors, but the future development of disciplines will be multi-faceted and interdisciplinary. This requires the joint advancement of multiple disciplines such as biomedicine, information communication, and embedded technology. Therefore, in the long run, a solid professional structure is likely to form a fixed mindset in scientific research, teaching, and management, which is not conducive to the creativity and long-term development of the team.

\subsection{Insufficient Attention to Teacher Training}

First-class universities are inseparable from first-class teachers, and the construction of a high-level talent team has become one of the important tasks of the current comprehensive reform of universities. The development of universities depends not only on advanced laboratory equipment and generous financial investment, but also on the number of influential academic leaders. At present, domestic colleges and universities often do not pay enough attention to the training of teachers. The phenomenon of attaching importance to the introduction of talents and despising teacher training is widespread. When recruiting teachers, they often show their enthusiasm for talents with high education, graduates from prestigious schools, or overseas study experience, but they do not pay attention to the follow-up training and development of teachers. Some schools only provide basic induction training and routine supervision and lectures for new teachers, but in fact young teachers are not clear about their career direction and self-positioning due to their short working hours, and they need to be more concerned about long-term scientific research innovation and professional growth. Therefore, blindly worshiping the introduction of talents and despising the normalization and continuous training of young teachers is one of the disadvantages of the construction of first-class undergraduates ${ }^{[3]}$.

\subsection{Difficulties in Improving Teacher Evaluation and Incentive Mechanisms}

The scientific management of the faculty is a prerequisite for achieving first-class professional goals. A sound evaluation and incentive system is conducive to the sustainable development of teachers and is of great significance for promoting the development of 
universities and improving the quality of higher education. At present, many colleges and universities in our country attach too much importance to academic qualifications and professional titles, or adopt a "one-size-fits-all" policy in teacher evaluation and incentive methods. "Title" and "Education" often represent the level of education, and the remuneration of teachers with talent titles is much higher than that of teachers without them. When designing evaluation standards, ignore the characteristics of different disciplines and different positions; focus only on explicit indicators such as teacher workload, number of funds, and the number of papers, and ignore teachers' hidden contributions. These are all barriers that hinder the development of teachers and the improvement of professional strength. Colleges and universities need to reform the evaluation and incentive mechanism, and specifically solve the problems of despising teaching and attaching importance to scientific research, the problems of professional characteristics and the matching of the evaluation system, and the problems of competence and willingness. In the incentive mechanism, it is necessary to consider the combination of ability factors, performance factors, and contribution factors, and design a compound incentive policy mechanism $^{[4]}$.

\section{THE CONSTRUCTION AND DEVELOPMENT OF TEACHER TEAMS IN SECONDARY COLLEGES OF APPLIED UNIVERSITIES}

\subsection{Optimize the Structure of Teaching Staff and Build Professional Clusters}

Establish a long-term mechanism for training young teachers, build a team of high-quality teachers, promote all-round innovation in education, teaching, and organization and management, and lay a solid foundation for continuous improvement of the level of schooling. The secondary colleges of applied universities should focus on national development strategies such as "innovation-driven development" and "Made in China 2025", and use comprehensive professional reform as the starting point to promote secondary colleges to adjust and optimize the structure of the faculty. By building a curriculum group with studios as the carrier, building professional clusters, group development, and exploring new ideas for talent training that integrates professionalism. Through measures such as the "dual leader system", "class teacher system", and "co-construction of teacher-student branches", the construction of the comprehensive ability of the teaching team has been strengthened.

\subsection{Create a Professional Team with Unique Advantages Closely Following the Characteristics of the Surrounding Industries}

On the one hand, establish a teacher training and development platform, such as encouraging young teachers to work in enterprises and institutions and visit high-level universities and research institutes at home and abroad, so that teachers can promote self-professional growth and improve engineering through mutual exchanges and learning, so as to further strengthen the construction of the teaching team. On the other hand, jointly build practical education centers with local governments, industries, enterprises and institutions, jointly build a cooperative training practical teaching platform, create a new mechanism for joint training of talents, and promote the integration of scientific research and teaching. Promote teaching research and teaching reform through various teaching activities, condense the professional characteristics suitable for market talents in the teaching reform, and create a professional team with unique advantages that closely follow the characteristics of the surrounding industries.

\subsection{Evaluation and Incentive Mechanism to Mobilize Teachers' Work Enthusiasm}

When considering evaluation and incentive mechanisms, it is necessary to respect the dominant status of teachers, strictly prevent biased evaluation methods and single incentive mechanisms, encourage teachers to participate in democratic management, and remove their worries in order to concentrate on scientific research and teaching without distraction. The scientific talent evaluation and incentive mechanism should avoid the tendency to underestimate teaching and overestimate scientific research, overcome the shortcomings of using papers or awards as the only evaluation factor, and adopt a combination of qualitative analysis and quantitative analysis and multiple methods for evaluation. Teaching and scientific research have the same weight and strengthen the awareness of scientific research quality, and adopt a flexible evaluation mechanism for different personnel or the nature of positions. Advocating competition among teaching and research sections not only mobilizes the enthusiasm of teachers, but also respects their autonomy, and stimulates the vitality of grassroots teaching organizations in form and system.

\section{CONCLUSION}

The process of "double first-class" construction is also the process of building first-class undergraduate education. Applied universities aim to cultivate applied 
undergraduate talents that meet the needs of industry development and serve the local economy, implement the spirit of "China Teaching Modernization 2035", and establish a team of high-quality and innovative teachers. Attach great importance to the introduction of self-owned teachers, the selection and employment of part-time teachers, and the training of young teachers. Gradually build a "full-time and part-time combination, stable and efficient, cooperative symbiosis, sustainable development" faculty team led by high-level academic leaders, a group of senior title teachers and outstanding young and middle-aged teachers as academic backbones, and a number of teachers with practical engineering experience in the industry. Improve relevant rules and regulations, encourage and guide young teachers to strengthen the tracking and research of new technologies, so that discipline construction, academic research, and talent training can be highly matched to industry changes. Improve the performance evaluation mechanism of teachers, adopt more incentive mechanisms, and urge and encourage teachers to fulfill their bounden duty of teaching and educating through various channels, and deepen the construction of "Double-type Teacher" team.

\section{FUND PROJECT}

The Stage Research Results of 2018 Jiangsu Provincial Department of Education University Philosophy and Social Science Research Fund Project 《 Construction of Evaluation Index of School-enterprise
Cooperation in Applied Talents Training》, Project Approval NO.2018SJA2077

\section{REFERENCES}

[1] Xu Xiuqin,Jin Jun,Zhang Nan,Yuan Dan.A Probe into the Construction of the Teaching Staff of Secondary Colleges in Colleges and Universities from the Perspective of "Double First Class" Construction[J].Theory and Practice of Education,2020,40(09):42-44.

[2] Zhang Xi,Gu Yongan,Zhang Genhua.Promotion Strategies for First-class Undergraduate Majors in Local Applied Universities__Based on a Survey of the Construction of Specialized Majors in 20 Universities in Jiangsu[J]. Chinese University Science \& Technology,2019(11):58-61.

[3] Xiaowei Wang, Yuqing Zhai,et al. Exploration and Practice of the Cultivation System of Computer Talents' Practice Ability in Independent Colleges[J]. Experimental Technology and Management, 2018,35(05):6-9.

[4] Liu Liusheng,Song Wenlong.Difficulties and Solutions for the Construction of First-class Undergraduate Majors in Local Universities in My Country $[\mathrm{J}]$. Journal of Yunnan Normal University(Humanities and Social Sciences Edition),2019,51(06):111-119. 